\title{
Development and evaluation of a pocket card to support prescribing by junior doctors in an English hospital
}

\author{
Matthew Reynolds $^{1} \cdot$ Elina Larsson $^{1} \cdot$ Richard Hewitt $^{2,3} \cdot$ Sara Garfield $^{1}$ • \\ Bryony Dean Franklin ${ }^{1}$
}

Received: 28 October 2014/Accepted: 8 April 2015/Published online: 12 May 2015

(c) The Author(s) 2015. This article is published with open access at Springerlink.com

\begin{abstract}
Background Junior doctors do most inpatient prescribing, with a relatively high error rate, and locally had reported finding prescribing very stressful. Objective To develop an intervention to improve Foundation Year 1 (FY1) doctors' experience of prescribing, and evaluate their satisfaction with the intervention and perceptions of its impact. Methods Based on findings of a focus group and questionnaire, we developed a pocket Dose Reference Card ("DrCard") for use at the point of prescribing. This summarised common drugs and dosing schedules and was distributed to all new FY1 doctors in a London teaching trust. A post-intervention questionnaire explored satisfaction and perceived impact. Results Focus group participants $(\mathrm{n}=12)$ described feeling anxious and time pressured when prescribing; a quick reference resource for commonly prescribed drug doses was suggested. Responses to the exploratory questionnaire reinforced these findings. Following Dr-Card distribution, the post-intervention questionnaire revealed that 29/38 (76\%) doctors were still using it 2 months after distribution and 38/38 (100\%) would recommend ongoing production. Conclusions FY1 doctors reported feeling stressed and time pressured when prescribing; this was perceived to contribute
\end{abstract}

Electronic supplementary material The online version of this article (doi:10.1007/s11096-015-0119-y) contains supplementary material, which is available to authorized users.

Matthew Reynolds

matthew.reynolds@nhs.net

1 Centre for Medication Safety and Service Quality, Imperial College Healthcare NHS Trust and UCL School of Pharmacy, London, UK

2 North West Thames Foundation School, London, UK

3 Department of Medicine, Imperial College London, London, UK to error. A pocket card presenting common drugs and doses was well-received, perceived to be useful, and recommended for on-going use.

Keywords Errors · Junior doctor - Medication ·

Prescribing $\cdot$ Reference source $\cdot$ Safety $\cdot$ United Kingdom

\section{Impact of findings on practice}

- Foundation Year 1 (FY1) doctors perceived time pressure and lack of access to information to be sources of stress and to potentially contribute to erroneous prescribing, suggesting these as areas for intervention.

- A locally relevant pocket reference guide developed with input from clinical pharmacists may be useful in improving FY1s' experience of prescribing; ours was widely used and recommended for ongoing use.

\section{Introduction}

Prescribing errors occur in up to $15 \%$ of medication orders in UK hospitals [1-6], comparable to international figures [7]. Interventions are therefore needed. There are many reasons why newly qualified Foundation Year 1 (FY1) doctors are a suitable target for such interventions. First, FY1 doctors do most of the prescribing in the UK hospital inpatient setting [4]. Second, while there is variation in reported junior doctors' prescribing error rates [8], FY1 doctors are reported to have a prescribing error rate twice that of consultants [4]. Third, they are more readily accessible as a group than their senior counterparts. Fourth, good prescribing habits learnt early will hopefully be retained throughout a doctor's career. 
Finally, FY1 doctors report lower confidence in their prescribing skills than FY2 doctors [9], identify that lack of knowledge of prescribing contributes to errors [10] and locally, reported finding prescribing very stressful with concerns about errors. We wanted to develop and evaluate an intervention to address these issues.

\section{Aims}

To investigate FY1s' views on prescribing, and develop and evaluate an intervention to improve their experience of prescribing.

\section{Ethical approval}

This work met criteria for local audit and improvement activities exempt from NHS ethics review, and was registered locally as an audit.

\section{Methods}

\section{Setting}

Initial development work took place across an educational organisation that provided training to $270 \mathrm{FY} 1$ doctors regionally. The intervention was then evaluated at a single London teaching hospital trust in which $82 \mathrm{FY} 1 \mathrm{~s}$ worked across three hospital sites. In line with most UK hospitals, FY1 doctors wrote a high proportion of inpatients' medication orders, which were handwritten onto preformatted paper drug charts.

\section{Developing the intervention}

We first conducted a focus group with 12 FY1s to explore FY1s' attitudes to prescribing, identify factors perceived as responsible for FY1 prescribing errors, and elicit potential solutions. The discussion was recorded, transcribed and thematically analysed.

Relevant topics identified were then explored further using an anonymous questionnaire (electronic supplementary material 1), distributed to all $270 \mathrm{FY} 1 \mathrm{~s}$ across the region. Respondents were asked about prescribing confidence and experiences of prescribing safety. Data were analysed descriptively.

\section{The intervention}

The focus group (Table 1) and questionnaire results suggested that an easily accessible reference source for local prescribing information would be a suitable intervention. We therefore created the Dose Reference Card ('Dr-Card') for commonly prescribed drugs and doses, for use at the point of prescribing when it was difficult to consult more detailed references. This was designed to be a low-cost intervention to improve FY1s' prescribing experience and support safe prescribing.

\section{Dr-Card design}

The resulting Dr-Card (Fig. 1) included the name, dose, and route of commonly prescribed adult inpatient drugs in our local formulary. Anti-infectives were excluded as separate resources for these exist locally.

Insulin sliding scale and warfarin initiation protocols were the most frequently searched terms on the prescribing guidelines intranet site; summaries of these were also included.

The draft contents were modified in response to suggestions from specialist clinical pharmacists and FY1 representatives. The final version was approved by the Drugs and Therapeutics Committee.

The Dr-Cards (2012 version) were printed on credit-card sized laminated cardboard designed to be carried within identification badge holders or pockets; they cost $£ 108$ for 100 cards.

\section{Dr-Card distribution}

The Dr-Card was distributed to FY1s during teaching sessions in August 2012, the first month of the FY1 year.

\section{Evaluation of the intervention}

We conducted a formal post-intervention evaluation to establish the extent to which FY1s were using the Dr-Card, their views on its content, format and potential impact and to identify suggestions for improvement.

We developed a questionnaire (electronic supplementary material 2) comprising open and closed questions. A FY2 doctor and pharmacists piloted the questionnaire and confirmed its face validity.

A pre-notification email was sent to all FY1s a week before questionnaire distribution. Questionnaires were distributed at FY1 teaching sessions in October 2012, as we were interested in experiences from the first months of FY1 prescribing. Questionnaires were sent to non-attendees via internal post; data were summarised descriptively and responses expressed using the number of respondents to each question as a denominator.

\section{Results}

\section{Focus group}

Participants described feeling anxious and under-prepared when prescribing (Table 1) and "daunted" at the beginning 
Table 1 Quotes from Foundation Year 1 doctor focus group

"I think it's difficult, because on the ward round there is that time issue, it's so quick from patient to patient, and often like they'll say to you prescribe this, and they'll move on". Quote 1

"But also I think certain things like insulin prescribing sliding scales and warfarin regimes, things that obviously they are very important, based on each patient's own clinical situation, there's not really, apart from the intranet and obviously the protocols on the intranet, there's no quick, fast sort of source that we can refer to on the ward round. So I think if there was something that was made more readily available to us". Quote 2

"I use this crib sheet, this was given to me by a CT1 [core trainee year 1 doctor] or something, it's been kept up to date, but it's just got, it's A4 [paper size], it's got all, all the antibiotics, with doses, IV [intravenous] and oral doses, anti-emetics, all your analgesia, laxatives, urology drugs, alcoholic drugs, chlordiazepoxide, inhalers and anxiolytics". Quote 3

Fig. 1 The 2 sides of the the Dr-CARD. Actual size is creditcard sized

\begin{tabular}{|c|c|c|c|}
\hline \multicolumn{4}{|c|}{ Analgesia-acute pain } \\
\hline \multirow{2}{*}{\multicolumn{2}{|c|}{$\begin{array}{l}\text { Paracetamol PO / PR } \\
\text { Paracetamol IV }>50 \mathrm{~kg}\end{array}$}} & $500 \mathrm{mg}-1 \mathrm{~g}$ & QDS \\
\hline & & $1 \mathrm{~g}$ & QDS \\
\hline \multirow{2}{*}{ Ibuprofen } & $\leq 50 \mathrm{~kg}$ & $15 \mathrm{mg} / \mathrm{kg}$ & QDS \\
\hline & PO & $400 \mathrm{mg}$ & TDS / QDS \\
\hline Naproxen & PO & $250 \mathrm{mg}$ & TDS / QDS \\
\hline Codeine & PO & $30-60 \mathrm{mg}$ & QDS \\
\hline Tramadol & $\mathrm{PO} / \mathrm{IM} / \mathrm{IV}$ & $50-100 \mathrm{mg}$ & QDS \\
\hline Morphine & PO & $5-10 \mathrm{mg}$ & 4 hourly \\
\hline Morphine & $\mathrm{IM} / \mathrm{SC}$ & $2.5-5 \mathrm{mg}$ & 4 hourly \\
\hline \multicolumn{4}{|c|}{ Antihistamines } \\
\hline \multirow{2}{*}{\multicolumn{2}{|c|}{$\begin{array}{l}\text { Chlorphenamine PO } \\
\text { Chlorphenamine IM / IV }\end{array}$}} & $4 \mathrm{mg}$ & TDS \\
\hline & & $10 \mathrm{mg}$ & QDS \\
\hline \multicolumn{4}{|c|}{ Antisecretory \& mucosal protectants } \\
\hline \multicolumn{2}{|c|}{ Omeprazole PO } & $20-40 \mathrm{mg}$ & $O D$ \\
\hline \multirow{2}{*}{\multicolumn{2}{|c|}{$\begin{array}{l}\text { Ranitidine PO } \\
\text { Lansoprazole PO }\end{array}$}} & $150 \mathrm{mg}$ & $O D / B D$ \\
\hline & & $15-30 \mathrm{mg}$ & $O D$ \\
\hline \\
\hline
\end{tabular}

\begin{tabular}{|c|c|c|c|}
\hline \multicolumn{4}{|c|}{ Laxatives } \\
\hline Senna & $\mathrm{PO}$ & $1-2$ tablets & $\mathrm{ON} / \mathrm{BD}$ \\
\hline Lactulose & PO & $15 \mathrm{ml}$ & $\mathrm{OD} / \mathrm{BD}$ \\
\hline Macrogol (L & axido) $\mathrm{PO}$ & $1-2$ sachets & $\mathrm{OD} / \mathrm{BD}$ \\
\hline Glycerol $4 \mathrm{~g}$ & PR & $1-2$ supps & PRN \\
\hline Phosphate & PR & 1 enema & PRN \\
\hline \multicolumn{4}{|c|}{ Antiemetics } \\
\hline \multicolumn{2}{|c|}{ Domperidone PO } & $10-20 \mathrm{mg}$ & TDS / QDS \\
\hline Cyclizine & $\mathrm{PO} / \mathrm{IM} / \mathrm{IV}$ & $50 \mathrm{mg}$ & TDS \\
\hline \multicolumn{3}{|c|}{ Metoclopramide PO / IM / IV 10mg } & TDS \\
\hline \multicolumn{2}{|c|}{ Ondansetron PO } & $8 \mathrm{mg}$ & $\mathrm{BD} / \mathrm{TDS}$ \\
\hline \multicolumn{2}{|c|}{ Ondansetron IM / N } & $4 \mathrm{mg}$ & $\mathrm{BD} / \mathrm{TDS}$ \\
\hline \multirow{3}{*}{\multicolumn{4}{|c|}{$\begin{array}{l}\text { LMW Heparin Is VTE assessment done? } \\
\text { Tinzaparin Red listed - GPs cannot prescribe } \\
\text { •DVT prophylaxis }\end{array}$}} \\
\hline & & & \\
\hline & & & \\
\hline \multicolumn{2}{|c|}{ eGFR $\geq 30 \mathrm{ml} / \mathrm{min}$} & \multicolumn{2}{|c|}{ SC 4,500units OD } \\
\hline \multirow{2}{*}{\multicolumn{2}{|c|}{$\begin{array}{c}\text { eGFR }<30 \mathrm{~m} / / \mathrm{min} \\
\text {.DVT/PE treatment }\end{array}$}} & \multicolumn{2}{|c|}{ SC 3,500 units OD } \\
\hline & & SC 175units & / $/ \mathrm{kg}$ OD \\
\hline
\end{tabular}

FY1 DOSE REMINDER CARD: typical adult doses. See BNF for full dose ranges. See The Source for Trust guidelines. In severe renal or hepatic impairment, seek pharmacy advice. Aug 2012; MR/BDF v16 ×30503

\begin{tabular}{|c|c|}
\hline $\begin{array}{l}\text { Insulin sliding scale } \\
\text { prescribed as } 50 \text { units of soluble insulin (e.g. Human } \\
\text { Actrapid) in } 50 \mathrm{ml} \text { sodium chloride } 0.9 \%\end{array}$ & $\begin{array}{l}\quad \text { Warfarin initiation protocol } \\
\text { Where anticoagulation not urgent (can } \\
\text { wait } 2 \text { weeks or more), consider referral to GP }\end{array}$ \\
\hline $\mathrm{BM}$ range $(\mathrm{mmol} / \mathrm{L})$ Insulin administration rate & Where inpatient anticoagulation needed: \\
\hline $\begin{array}{r}0.5 \text { units/hour } \\
\text { (recheck every } 15 \text { mins) }\end{array}$ & $\begin{array}{l}\text { Start on } 5 \mathrm{mg} \text { OD on day } 1 \text {, and refer to The } \\
\text { Source for dosing thereafter. Crowther protocol } \\
\text { preferred for medically unstable patients, or Tait }\end{array}$ \\
\hline 1 units/hour & for medically stable patients not requiring frequent \\
\hline 2 units/hour & $\begin{array}{l}\text { monitoring, likely to be inpatient >bdays, and } \\
\text { outpatients. }\end{array}$ \\
\hline 3 units/hour & - Consider lower starting dose if $>75 \mathrm{yrs},<55 \mathrm{~kg}$, \\
\hline 4 units/hour & cardiac/hepatic failure, severe renal impairment, \\
\hline 6 to 8 units/hour & on interacting drugs. \\
\hline (If $>20 \mathrm{mmol} / \mathrm{L}$ for 2 hours contact medical staff) & - Consider higher starting dose if $>100 \mathrm{~kg}$, on \\
\hline $\begin{array}{l}\text { Not for use in patients with HONK, in level } 2 \text { or } 3 \\
\text { patients, or in theatre or recovery }\end{array}$ & \\
\hline
\end{tabular}

For enquiries contact the WARD PHARMACIST or MEDICINES INFORMATION Ext: 11703/11713. Out of hours contact the on-call pharmacist via switchboard.
Imperial College Healthcare W/HS 
of their FY1 year. Some expressed concern about getting "the simple things" wrong, both practically (e.g. missing signatures) and clinically (e.g. doses). FY1s described time pressure (quote 1) as one of the difficulties, for example not having sufficient time to look up doses to check they were prescribing correctly.

Participants identified that a quick reference 'crib sheet' would be a useful resource to enable them to look up commonly prescribed doses quickly (quote 2). Some had already developed their own (quote 3).

\section{Exploratory questionnaire}

Seventy-eight (29\%) of 270 FY1 doctors from the region completed the exploratory questionnaire. One of the most frequently reported reasons for erroneous prescribing was time pressure (48/73 respondents to this question; $66 \%$ ); six $(8 \%)$ stated that lack of informative resources influenced erroneous prescribing. Other frequently chosen reasons for erroneous prescribing were lack of knowledge of the patient, and lack of pharmaceutical knowledge; these will be addressed in future interventions.

\section{The Dr-Card}

A total of 77 (94\% of all $82 \mathrm{FY} 1 \mathrm{~s}$ at ICHT) received the Dr-Card. Forty-three of 82 (52\%) FY1s completed the post-implementation questionnaire, of whom 41 (95\%) had received a Dr-Card and 29/38 respondents (76 \%) were still using it at the time of the survey (Table 2). Four respondents who stated they "never" used it had lost their card, and one was based in paediatrics where it was not applicable.

Thirty-seven ( $88 \%$ ) of 42 respondents reported being satisfied or very satisfied with the material, colour and size of the card; none were dissatisfied. The majority of respondents $(28 / 42 ; 67 \%)$ wanted the card to be available as both a plastic card and smartphone application.

Most $(30 / 40 ; 75 \%)$ respondents reported using the individual drugs' dosing guidelines; 17/41 (41\%) reported having used the insulin sliding scale and 12/40 (30\%) the warfarin initiation protocol. One respondent reported using the intranet guidelines instead.

Twenty (91\%) of 22 respondents thought the Dr-Card would improve patient safety, two (9\%) disagreed. Reasons given for improving safety included correct dosing, quicker access to medication for patients and reduced stress levels. One respondent stated that the British National Formulary (BNF) was available and would be used instead, and another that the Dr-Card would only improve safety if it was kept up-to-date and used alongside the BNF.

Finally, $38(100 \%)$ of 38 respondents thought the DrCard should be produced next year; one added that it was particularly helpful in clinical areas where common drugs had to be prescribed quickly. Some suggested additional drugs and/or protocols for inclusion.

Table 2 Responses to post-implementation questionnaire

\begin{tabular}{|c|c|c|c|c|c|c|c|c|}
\hline & & Daily & Weekly & \multicolumn{2}{|c|}{ Less than weekly } & Never & Total $^{\mathrm{a}}$ & No answer \\
\hline \multirow{2}{*}{\multicolumn{2}{|c|}{$\begin{array}{l}\text { How often did you use your Dr-Card at first? } \\
\text { How often do you use your Dr-Card now? }\end{array}$}} & $18(45 \%)$ & $10(25 \%)$ & $5(13 \%)$ & & $7(18 \%)$ & $40(100 \%)$ & 3 \\
\hline & & $6(16 \%)$ & $17(45 \%)$ & $6(16 \%)$ & & $9(24 \%)$ & $38(100 \%)$ & 5 \\
\hline & Very satisfied & Satisfied & Neutral & Unsatisfied & $\mathrm{Ve}$ & unsatisfied & Total & No answer \\
\hline \multirow{2}{*}{$\begin{array}{l}\text { How satisfied are you with the } \\
\text { material of the Dr-Card? }\end{array}$} & $21(50 \%)$ & $16(38 \%)$ & $5(12 \%)$ & $0(0 \%)$ & \multicolumn{2}{|c|}{$0(0 \%)$} & $42(100 \%)$ & 1 \\
\hline & Plastic & Smartphone & \multicolumn{2}{|c|}{ Both } & \multicolumn{2}{|c|}{ No preference } & Total & No answer \\
\hline \multirow{2}{*}{$\begin{array}{l}\text { What format would you prefer } \\
\text { Dr-Card to be produced in? }\end{array}$} & $8(19 \%)$ & \multirow[t]{2}{*}{$4(10 \%)$} & \multicolumn{2}{|c|}{$28(67 \%)$} & \multicolumn{2}{|c|}{$2(5 \%)$} & $42(100 \%)$ & 1 \\
\hline & & & \multicolumn{2}{|l|}{ Yes } & \multicolumn{2}{|l|}{ No } & Total & No answer \\
\hline \multicolumn{3}{|c|}{$\begin{array}{l}\text { Have you used the dosing guidelines for the individual drugs } \\
\text { listed on the Dr-Card? }\end{array}$} & \multicolumn{2}{|c|}{$30(75 \%)$} & \multicolumn{2}{|c|}{$10(25 \%)$} & $40(100 \%)$ & 3 \\
\hline \multicolumn{3}{|c|}{ Have you used the insulin sliding scale on the Dr-Card? } & \multicolumn{2}{|c|}{$17(41 \%)$} & \multicolumn{2}{|c|}{$24(59 \%)$} & $41(100 \%)$ & 2 \\
\hline \multicolumn{3}{|c|}{ Have you used the warfarin initiation protocol on the Dr-Card? } & \multicolumn{2}{|c|}{$12(30 \%)$} & \multicolumn{2}{|c|}{$28(70 \%)$} & $40(100 \%)$ & 3 \\
\hline \multicolumn{3}{|c|}{ Will the Dr-Card improve patient safety? } & \multicolumn{2}{|c|}{$20(91 \%)$} & \multicolumn{2}{|c|}{$2(9 \%)$} & $22(100 \%)$ & 21 \\
\hline \multicolumn{3}{|c|}{ Should the Dr-Card be produced next year? } & \multicolumn{2}{|c|}{$38(100 \%)$} & \multicolumn{2}{|c|}{$0(0 \%)$} & $38(100 \%)$ & 5 \\
\hline
\end{tabular}

${ }^{a}$ Percentages are calculated using the number of responses to that individual question as the denominator 


\section{Discussion}

A focus group and exploratory questionnaire suggested that a resource for use under time pressure may be helpful to FY1 doctors when prescribing. As some FY1s had already created their own reference sources, we formalised a novel, quick, low-cost 'Dr-Card', in line with local guidelines, which was distributed to all FY1s in one trust. Although dosing information and clinical guidelines are available on the trust's intranet, doctors have intermittent access to a computer when prescribing: the Dr-Card therefore provides an accessible summary. Its portability and local relevance also complements the use of textbooks and tablet computers.

A post-implementation questionnaire revealed the majority of FY1 doctors viewed the Dr-Card positively, felt it improved safety and were still using it 2 months after distribution. All respondents thought production of the DrCard should continue. Patterns of use suggest the Dr-Card was used less over time, perhaps as FY1s gain experience.

\section{Strengths and limitations}

Strengths of our study are that we developed a low-cost, practical intervention and evaluated its acceptability and perceived impact. We recognise that our intervention was based on focus group and questionnaire data from a relatively small cohort, that the questionnaire had only a $52 \%$ response rate and that we do not have comparative demographic data for respondents and non-respondents. The evaluation was limited as we were not funded to evaluate the effect of the Dr-Card on prescribing errors.

\section{On-going work}

Based on the evaluation, we produced an updated Dr-Card for future intakes of FY1s, presented as a more robust plastic card and also incorporated the information into a local smartphone application. Drugs and doses are reviewed annually by clinical pharmacists, FY1s and senior doctors, to ensure they remain aligned with local practice and relevant guidelines. Future research should explore the effect of quick reference guides such as the Dr-Card on prescribing errors.

\section{Conclusions}

FY1 doctors reported feeling stressed and time pressured when prescribing; this was perceived to contribute to error. We developed the Dr-Card as a low cost intervention to provide key information at the point of prescribing. The majority of FY1 doctors carried, used, and liked the DrCard and thought it should be produced again. The Dr-Card is now embedded into local practice.
Acknowledgments We are grateful to Helen Bell for her assistance in preparing the manuscript.

Funding This study had no specific source of funding. The Centre for Medication Safety and Service Quality is affiliated with the National Institute for Health Research (NIHR) Imperial Patient Safety Translational Research Centre and the NIHR Health Protection Research Unit in Healthcare Associated Infection and Antimicrobial Resistance at Imperial College London in partnership with Public Health England (PHE). The views expressed are those of the author(s) and not necessarily those of the NHS, the NIHR, the PHE or the Department of Health.

\section{Conflicts of interest None.}

Open Access This article is distributed under the terms of the Creative Commons Attribution 4.0 International License (http:// creativecommons.org/licenses/by/4.0/), which permits unrestricted use, distribution, and reproduction in any medium, provided you give appropriate credit to the original author(s) and the source, provide a link to the Creative Commons license, and indicate if changes were made.

\section{References}

1. Dean BS, Schachter M, Vincent C, Barber ND. Prescribing errors in hospital inpatients: their incidence and clinical significance. Qual Saf Healthc. 2002;11(4):340-4.

2. Donyai P, O'Grady K, Jacklin A, Barber ND, Franklin BD. The effects of electronic prescribing on the quality of prescribing. Br J Clin Pharmacol. 2008;65(2):230-7.

3. Franklin BD, O’Grady K, Paschalides C, Utley M, Gallivan S, Jacklin A, et al. Providing feedback to hospital doctors about prescribing errors; a pilot study. Pharm World Sci. 2007;29(3): 213-20.

4. Dornan T, Ashcroft D, Lewis P, Miles J, Taylor D, Tully M, et al. An in depth investigation into causes of prescribing errors by foundation trainees in relation to their medical education. EQUIP study. London; 2009. p. 1-215. http://www.gmc-uk.org/FINAL_ Report_prevalence_and_causes_of_prescribing_errors.pdf_2893 5150.pdf. Accessed 02 Oct 2015.

5. Franklin BD, Reynolds M, Shebl NA, Burnett S, Jacklin A. Prescribing errors in hospital inpatients: a three-centre study of their prevalence, types and causes. Postgrad Med J. 2011; 1033(87):739-45.

6. Seden K, Kirkham JJ, Kennedy T, Lloyd M, James S, McManus A, et al. Cross-sectional study of prescribing errors in patients admitted to nine hospitals across North West England. BMJ Open. 2013;3(1).

7. Lewis PJ, Dornan T, Taylor D, Tully MP, Wass V, Ashcroft DM. Prevalence, incidence and nature of prescribing errors in hospital inpatients: a systematic review. Drug Saf. 2009;32(5):379-89.

8. Ross $\mathrm{S}$, Bond $\mathrm{C}$, et al. What is the scale of prescribing errors comitted by junior doctors? A systematic review. Br J Clin Pharmacol. 2009;67(6):629-40.

9. Ryan C, Ross S, et al. Junior doctors' perceptions of their selfefficacy in prescribing, their prescribing errors and the possible causes of errors. Br J Clin Pharmacol. 2013;76(6):980-7.

10. Lewis PJ, Ashcroft DM, et al. Exploring the causes of junior doctors' prescribing mistakes: a qualitative study. Br J Clin Pharmacol. 2014;78(2):310-9. 